\title{
Terpenoids are transported in the xylem sap of Norway spruce
}

\author{
Qiuxiao Duan ${ }^{1}$, Boris Bonn² ${ }^{2}$ and Juergen Kreuzwieser ${ }^{3}$ \\ ${ }^{1}$ Institute of Forest sciences \\ ${ }^{2}$ Chair of Ecosystem Physiology \\ ${ }^{3}$ University of Freiburg
}

May 5, 2020

\begin{abstract}
Norway spruce is a conifer storing large amounts of terpenoids in resin ducts of various tissues. Parts of the terpenoids stored in needles can be emitted together with de novo synthesized terpenoids. Since previous studies provided hints on xylem transported terpenoids as a third emission source, we tested if terpenoids are transported in xylem sap of Norway spruce. We further aimed at understanding if they might contribute to terpenoid emission from needles. We determined terpenoid content and composition in xylem sap, needles, bark, wood and roots of field grown trees, as well as terpenoid emissions from needles. We found considerable amounts of terpenoids - mainly oxygenated compounds - in xylem sap. The terpenoid concentration in xylem sap was relatively low compared to the content in other tissues where terpenoids are stored in resin ducts. Importantly, the terpenoid composition in the xylem sap greatly differed from the composition in wood, bark or roots suggesting that an internal transport of terpenoids takes place at the sites of xylem loading. Our work gives hints that plant internal transport of terpenoids exists within conifers; studies on their functions should be a focus of future research.
\end{abstract}

\section{Key words:}

Norway spruce, terpenoid transport, xylem sap, emissions, roots

\section{Introduction}

Terpenoids constitute the largest and most diverse class of chemical substances that play major roles in plant primary and secondary metabolisms (Gershenzon \& Dudareva, 2007; Nagel, Berasategui, Paetz, Gershenzon \& Schmidt, 2014; Trapp \& Croteau, 2001). Two spatially separated pathways exist for the biosynthesis of terpenoids; the mevalonate (MVA) pathway takes place in cytosol and peroxisomes, whereas the methylerythritol phosphate (MEP) pathway is active in plastids (Dudareva, Klempien, Muhlemann, \& Kaplan, 2013; Nagegowda, 2010). Both pathways form the C5 compounds isopentenyl diphosphate (IPP) and its allylic isomer, dimethylallyl diphosphate (DMAPP), which act as precursors for the biosynthesis of all terpenoids (McGarvey \& Croteau, 1995). Whereas the MVA pathway produces sesquiterpenes (C15), irregular terpenes and geranyllinalool, the MEP pathway forms hemiterpenes (C5), monoterpenes (C10), diterpenes (C20) and volatile carotenoid derivatives (McGarvey \& Croteau, 1995; Muhlemann, Klempien \& Dudareva, 2014). Terpenoids can be stored in specialized structures such as resin ducts in many conifers (Gershenzon \& Croteau, 1991; Wu \& Hu, 1997) or directly emitted into the environment (Loreto et al., 2001). In storing plants, terpenoids usually make up 1-2\% of plant dry weight, in some special cases shares of up to 15-20\% were observed (Blanch, Penuelas, Sardans \& Llusia, 2009). Terpenoids exert key ecological functions for plants, such as defence against predators, pathogens or competitors, inter- and intraspecific communication as well as 
protection against abiotic stress (Gershenzon \& Dudareva, 2007; Loreto \& Schnitzler, 2010; Loreto, Pollastri, Fineschi \& Velikova, 2014; Martin, Gershenzon \& Bohlmann, 2003; Vickers et al., 2009).

According to present knowledge, there are two sources driving terpenoid emission from leaves of plants. (i) $D e$ novo biosynthesis controls emission of isoprene and terpenoids from non-storing plants such as Quercus ilex . Production of these compounds is tightly coupled to photosynthesis and therefore shows similar dependencies on environmental parameters such as light availability and temperature (Ghirardo et al., 2010; Loreto et al., 1996; Loreto, Nascetti, Graverini \& Mannozzi, 2000; Tingey, Manning, Grothaus \& Burns, 1979). On the other hand, (ii) the release of leaf-internally stored terpenoids is purely temperature dependent because temperature controls the corresponding saturation vapour pressures of the emitted compounds (Ghirardo et al., 2010; Guenther, Zimmerman, Harley, Monson \& Fall, 1993; Wu et al., 2017).

As a typical conifer, Norway spruce (Picea abies) stores large amounts of terpenoids in resin ducts of various tissues, which are at least partially produced in the epithelial cells of the resin ducts and mesophyll tissue (Schürmann, Ziegler, Kotzias, Schönwitz \& Steinbrecher, 1993). ${ }^{13} \mathrm{C}$-labelling approaches demonstrated that about one third of the emitted monoterpenoids in spruce are derived from de novo biosynthesis whereas the remainder is released from storage pools in a temperature depended manner (Ghirardo et al., 2010; Grabmer et al., 2006). Recent studies provided indirect hints that besides de novo biosynthesis and/or release from storage pools, xylem-transported terpenoids might contribute to emission from Norway spruce needles. Bourtsoukidis et al. $(2012,2014)$ observed that sesquiterpene (SQT) emission from Norway spruce strongly correlated with relative humidity. At high relative humidity - and consequently reduced transpiration rates SQT emission was slowed down and vice versa when relative humidity was below $50 \%$ (Bourtsoukidis et al., 2012). In agreement with this finding, Filella, Wilkinson, Llusia, Hewitt \& Peñuelas (2007) demonstrated that the emissions of most volatile organic compounds including monoterpenes from Norway spruce were well related to stomatal conductance and transpiration. This effect may in part be explained by a contribution of the tree's sap flow to terpenoid emissions. Moreover, Bäck et al. (2012) found the largest SQT pools in Pinus sylvestris not in needles but below the bark, where SQTs constitute a toxic barrier for bark beetles and function as stress defense agents. Such terpenes might partially be released into the xylem sap. This assumption is in consistence with observations of Kuroda (1991) who observed a strong link between xylem cavitation in pine wilt disease infected Pinustrees and terpene abundance in the xylem. The author hypothesizes that cavitation is caused by higher terpene content in the xylem sap and the thereby diminished adhesion forces. A strong induction of terpene biosynthesis in the developing xylem by different stresses has also been demonstrated in Norway spruce (Martin, Tholl, Gershenzon \& Bohlmann, 2002).

In this study, we aim at clarifying whether or not terpenoids are transported in the xylem sap of Norway spruce. Moreover, we aimed to obtain information on possible sources of xylem-transported terpenoids. In addition, we tried to find hints if xylem-transported terpenoids might contribute to terpenoid emission from Norway spruce needles.Therefore, we analyzed terpenoid emission rates as well as terpenoid contents and compositions in root, bark and wood of the same Norway spruce trees for comparison with xylem sap terpenoids.

\section{Materials and methods}

\section{Study site}

In September 2015, we studied six clonal 13-year-old Norway spruce trees grown in the tree garden of the Chair of Ecosystem Physiology, University of Freiburg, Germany (48 $01^{\prime}$ N, 7deg50' E, $236 \mathrm{~m}$ above sea level) under the natural temperate to cool-temperate climate. In 2015, the average monthly mean of daily temperature in $2 \mathrm{~m}$ height was $11.8+-1.9 \mathrm{degC}$, which was $0.4 \mathrm{deg} \mathrm{C}$ higher than the 30 year average; total annual precipitation of $732 \mathrm{~mm}$ was about $200 \mathrm{~mm}$ less than the long-term reference (1981- 2010) (DWD, 2015; Table S1). 


\section{Analysis of terpenoid emission}

Terpenoid emission was determined using a modified dynamic leaf enclosure system of Kreuzwieser et al. (2001) under ambient conditions at internal enclosure temperatures between 22 and 34degC. In the evening before emission measurements, the glass enclosure (volume $500 \mathrm{ml}$, Duran, Mainz, Germany) was mounted onto a healthy, sun-exposed Norway spruce branch about $60 \mathrm{~cm}$ above ground. It was taken care to avoid any mechanical injuries on needles and stems to minimize release of terpenes. The lid of the enclosure remained open until the start of the experiment. At least 15 min before terpenoid collection was started, the lid was closed and the enclosure continuously flushed with synthetic air containing $400 \mathrm{ppm} \mathrm{CO}_{2}$ at flow rates of $200 \mathrm{ml} \mathrm{min}{ }^{-1}$. A fan (DC series, Sunon, Taiwan) installed in the enclosure ensured homogeneous air mixture. Terpenoids were collected from air leaving the enclosure. For this purpose, we installed air sampling tubes (Gerstel, Mulheim, Germany) filled with $20 \mathrm{mg}$ Tenax TA 60/80 and $30 \mathrm{mg}$ Carbotrap B 20/40 (Supelco, Belafonte, PA, USA) as adsorbents at the enclosure exit. Enclosure air was drawn by an air sampling pump (model 210-1003MTX, SKC, Dorset, UK) at a flow rate of $100 \mathrm{ml} \mathrm{min}^{-1}$ for 60 min over the air sampling tubes. All tubing of the system was made of perfluoralkoxy (PFA) (Swagelok, Solon, Ohio, USA) to prevent adhesion on or reaction of terpenoids with tubing materials. As a reference, air was also sampled from an empty enclosure which was flushed with the same synthetic air. The air sampling tubes were then stored in glass vials at $4 \mathrm{degC}$ until terpenoid analysis (see below). Terpenoid emission rates were calculated considering the amount of terpenoids on air sampling tubes, dry weight of needles in the enclosure and, sampling time and flow rate through the enclosure; data were background corrected by measurements of the empty enclosure.

\section{Harvest of plant material}

Immediately after collection of needle released terpenoids, a sun exposed branch of about $40-45 \mathrm{~cm}$ length (diameter ca. $1 \mathrm{~cm}$ ) which was closely located to the branch for emission measurements, was cut and xylem sap was extracted (Rennenberg, Schneider \& Weber, 1996). Special care was taken to avoid contamination of xylem sap with bark or wood constituents. For this purpose, bark and cambium were removed at a length of ca. $3 \mathrm{~cm}$ from the cut end; this part was rinsed thoroughly with distilled water and methanol, and dried with cellulose paper before it was inserted into the pressure chamber. The pressure was raised at a rate of 0.2 MPa per min until the first droplet of xylem sap appeared. This droplet was discarded and the end cleaned again with methanol. Thereafter, the pressure was increased by another 0.5-0.7 MPa and kept constant for about 2 mins; drops appearing were collected and immediately shock-frozen in liquid $\mathrm{N}_{2}$ until terpenoid analysis.

Samples of current- and previous-year needles, bark and wood from sun exposed twigs close to the twig which was used for xylem sap extraction, as well as fine roots (diameter $<2 \mathrm{~mm}$ ) of the same trees were harvested. All plant materials were immediately shock-frozen in liquid $\mathrm{N}_{2}$, and stored at $-80 \mathrm{degC}$. Before terpenoid analysis, plant materials were homogenized to fine powders by mortar and pestle under liquid $\mathrm{N}_{2}$.

For determination of tissue dry weights, aliquots of approximately $100 \mathrm{mg}$ frozen needle, bark, wood or root powders were dried at $60 \mathrm{deg} \mathrm{C}$ until the weight remained constant. Contents of all parameters were calculated based on dry weight unless indicated otherwise.

\section{Terpenoid extraction from xylem sap}

Terpenoid extraction was mediated by stir bar sorptive extraction (SBSE) using polydimethylsiloxane (PDMS)-coated stir bars (Twisters(r), $0.5 \mathrm{~mm}$ PDMS layer thickness, $10 \mathrm{~mm}$ in length, Gerstel, Mulheim, Germany) (Kleiber et al., 2017). To trap terpenoids, one Twister(r) was added into an aliquot of $300 \mu l$ xylem sap and samples were shaken $\left(1,400 \mathrm{rpm}, 30^{\circ} \mathrm{C}\right.$; Thermomixer, Eppendorf AG, Hamburg, Germany) for $60 \mathrm{~min}$. Thereafter, we removed the Twister@ from the solution, shortly dried it with lint-free paper tissue and placed it into a thermodesorption tube (Gerstel, Müllheim, Germany) for terpenoid analysis. 


\section{Terpenoid extraction from plant tissues}

Aliquots of $25 \mathrm{mg}$ of frozen powder were added into 1,500 $\mu \mathrm{l}$ methanol. Samples were shaken (1,400 rpm, $\left.30^{\circ} \mathrm{C}, 20 \mathrm{~min}\right)$ and centrifuged $\left(15,000 \mathrm{rpm}, 23^{\circ} \mathrm{C}, 5 \mathrm{~min}\right)$. Supernatants were diluted (bark, 1:50, other tissues, 1:33.3) in $\mathrm{H}_{2} \mathrm{O}_{\text {demin }}$ and two Twisters $\mathrm{R}$ were added to $1.5 \mathrm{ml}$ solution. Samples were shaken again $\left(1,400 \mathrm{rpm}, 30^{\circ} \mathrm{C}, 60 \mathrm{~min}\right)$ and Twisters $\AA$ thereafter taken out, dried with lint-free paper tissue and placed into a thermodesorption tube (Gerstel, Mülheim, Germany) for subsequent analysis of terpenoids.

\section{Terpenoid analysis}

Terpenoids adsorbed on Twisters $\mathbb{R}$ (xylem sap, tissues) as well as on air sampling tubes (emission) were analyzed on a gas chromatograph (GC) (model 6890A, Agilent, Waldbronn, Germany) equipped with a thermodesorption/cold injection system (TDU-CIS) (Gerstel, Mülheim, Germany) and connected to a MS detector (5975C, Agilent) (Kleiber et al., 2017). In the TDU, thermodesorption tubes containing Twisters $\mathbb{R}$. or air sampling tubes were heated up to $220^{\circ} \mathrm{C}$ to release the terpenoids adsorbed. A He gas stream channeled the terpenoids into the CIS where they were cryo-focused at $-50^{\circ} \mathrm{C}$. Subsequently, the CIS was heated up to $240^{\circ} \mathrm{C}$ to release the terpenoids onto the separation column (DB-5, Agilent) at a He flow of $1 \mathrm{ml}$ $\mathrm{min}^{-1}$. Oven temperature program and MS settings were exactly as described by Kleiber et al. (2017). Raw data files were processed with the Agilent MassHunter Software (Agilent, Waldbronn, Germany). For compound identification, mass spectra were searched in the MS spectral databank NIST (National Institute of Standards and Technology, Gaithersburg, MD, USA) and by external terpenoid standards. Peak alignment was manually checked. Terpenoids were quantified with calibration curves of representative terpenoids (i.e ., $\alpha$-pinene for monoterpenes, $\alpha$-humulene for sesquiterpenes and diterpenes and 1,8-cineole for oxygenated terpenoids).

\section{Statistics}

To test significant differences of total terpenoid contents among different tissues, statistical analyses were performed using SigmaPlot 11.0 (Systat Software GmbH, Erkrath, Germany). Since neither normality distribution nor equal variance was given even when data were log- or square-root transformed, we applied the Kruskal Wallis One Way Analysis of Variance on Ranks followed by Dunn's Method for all pairwise multiple comparisons. Differences were considered significant at $\mathrm{p}<0.05$. In order to compare the different tissue samples and xylem sap samples for terpenoid patterns, partial least-square discriminant analysis (PLSDA) was performed using the freely available web based software package MetaboAnalyst 4.0 (Chong et al., 2018, http://www.metaboanalyst.ca). Before running PLS-DA, raw data of terpenoid concentrations in xylem sap, needles, bark, wood and roots were subjected to a natural logarithm transformation ('generalized logarithm transformation') within MetaboAnalyst 4.0.

\section{Results}

\section{Numerous oxygenated terpenoids are abundant in xylem sap}

A considerable amount of terpenoids was abundant in the trees' xylem sap. We identified 44 terpenoids making up a total concentration of $6.4 \pm 0.9 \mu \mathrm{g} \mathrm{mL}-1$ (Figure 1A). The majority of the compounds were oxygenated terpenoids constituting $85 \%$ of total terpenoids (i.e. oxygenated monoterpenoids, MT-Os: 74\%; oxygenated sesquiterpenoids, SQT-Os: $8 \%$; oxygenated diterpenoids, DT-Os: $3 \%$ ), whereas terpenes formed a smaller fraction (monoterpenes, MTs: 13\%; SQTs: 2\%; diterpenes, DTs: <0.1\%) (Figure 1D). Linalool was the most abundant compound ( $20 \%$ of total terpenoids), followed by trans-sabinene hydrate (9\%), terpinen-4-ol (8\%) and camphor (7\%) (Figure 2C). The most abundant MT was $\beta$-pinene (4\% of total terpenoids), followed by terpinolene (3\%), $\alpha$-pinene $(2 \%)$ and $\delta$-3-carene $(2 \%)$ (Figure 3C). Surprisingly, we also identified five SQTs (i.e ., $\alpha$-farnesene, muuroladiene, $\delta$-cadinene, $\beta$-caryophyllene and longifolene) in the 
xylem sap, however, at very low amounts (Figure 4C). Besides, the three oxygenated SQTs oplopanone (4\%), $\delta$-cadinol $(2 \%)$ as well as longiborneol (1\%) were present (Figure 5C). We also observed the DT biformene $(<1 \%)$ and the oxygenated DTs manoyl oxide $(2 \%)$ and sclareol $(2 \%)$ in xylem sap (Table S2).

\section{Terpenoid emission from spruce needles}

Needles emitted 55 terpenoids at a rate of 1,709 $\pm 248 \mathrm{ng} \mathrm{g}^{-1} \mathrm{DW} \mathrm{h}^{-1}$ (Figure 1B). The composition consisted of $32 \%$ MTs, $46 \%$ MT-Os, $18 \%$ SQTs, $2 \%$ SQT-Os and traces of DTs and DT-Os (Figure 1E). The quantitatively most important MT-Os emitted were camphor $\left(210 \pm 88 \mathrm{ng} \mathrm{g}^{-1} \mathrm{DW} \mathrm{h}^{-1}\right)$, borneol $\left(141 \pm 36 \mathrm{ng} \mathrm{g}^{-1} \mathrm{DW} \mathrm{h}^{-1}\right)$ and linalool (113 $\pm 13 \mathrm{ng} \mathrm{g}^{-1} \mathrm{DW} \mathrm{h}^{-1}$ ) (Figure 2A). Moreover, the MTs camphene $\left(170 \pm 67 \mathrm{ng} \mathrm{g}^{-1} \mathrm{DW} \mathrm{h}^{-1}\right)$, $\alpha$-pinene $\left(164 \pm 45 \mathrm{ng} \mathrm{g}^{-1} \mathrm{DW} \mathrm{h}^{-1}\right), \beta$-pinene $\left(86 \pm 16 \mathrm{ng} \mathrm{g}^{-1} \mathrm{DW} \mathrm{h}^{-1}\right)$ as well as limonene $\& \beta$-phellandrene $\left(66 \pm 21 \mathrm{ng} \mathrm{g}^{-1} \mathrm{DW} \mathrm{h}^{-1}\right)$ were strongly released (Figure 3A). The most abundant SQT emitted from Norway spruce needles was $\alpha$-longipinene $\left(69 \pm 50 \mathrm{ng} \mathrm{g}^{-1} \mathrm{DW} \mathrm{h}^{-1}\right)$, followed by $\alpha$-farnesene $\left(45 \pm 25 \mathrm{ng} \mathrm{g}^{-1} \mathrm{DW} \mathrm{h}^{-1}\right), \beta$ -

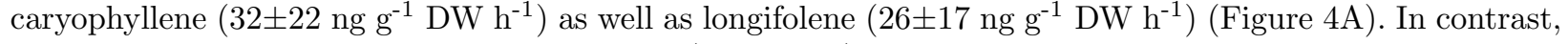
needles emitted SQT-O at relatively low rates (Figure 5A).

\section{Terpenoid content in spruce tissues}

Multivariate analysis (PLS-DA) of Norway spruce tissues showed separation into individual clusters indicating different terpenoid compositions (Figure 6). The respective loading plots highlighted the compounds responsible for clustering (Figure S1). Carvone (no '18', of the loading plot as listed in Table S3), $\alpha$-farnesene ('29') and the oxygenated SQT longiborneol ('43') were the main drivers for separation of sap from tissues. Differently, bornyl acetate ('26'), nerolidol ('44') and $\alpha$-cadinol ('45') were responsible for the cluster formation of needle and bark samples. In contrast, $\boldsymbol{\gamma}$-decalactone (' 22 '), linalool formate ('23') and isoborneol ('24') were the main drivers for clustering of wood and root samples.

Besides composition, also total terpenoid contents differed strongly among different tissues, amounting to $126 \pm 13 \mathrm{mg} \mathrm{g}^{-1} \mathrm{DW}$ in bark, $163 \pm 33 \mathrm{mg} \mathrm{g}^{-1} \mathrm{DW}$ in current-year needles, $29 \pm 2 \mathrm{mg} \mathrm{g}^{-1} \mathrm{DW}$ in roots and $13 \pm 2$ $\mathrm{mg} \mathrm{g}^{-1} \mathrm{DW}$ in wood (Figure 1C). In total, 82 different terpenoids were detected in bark; $78 \%$ were terpenes (72\% MT, $5 \%$ SQT, $1 \%$ DT) and $22 \%$ oxygenated terpenoids (4\% MT-O, 1\% SQT-O, 17\% DT-O) (Figure $1 \mathrm{~F})$. The most abundant MTs in bark were $\beta$-pinene $(34 \%), \alpha$-pinene (19\%), limonene $\& \beta$-phellandrene $(9 \%)$ (Figure 3D), whereas bornyl acetate $(2 \%)$ dominated the MT-O fraction (Figure 2D). In addition, in bark $\beta$-caryophyllene (1\%), $\alpha$-longipinene (1\%) and longifolene (1\%) were the most abundant SQTs (Figure 4D), whereas $\delta$-cadinol $(<1 \%)$ and nerolidol $(<1 \%)$ dominated the SQT-O fraction in bark (Figure 5D). Seven DTs and 12 oxygenated DT were also observed, with pimaric acid (6\%), abietic acid (3\%) and manool $(3 \%)$ being the most abundant DT-Os in bark of Norway spruce.

Differently from bark, 56 terpenoids were identified in the wood; MT (78\% of all terpenoids) and MT-O $(12 \%)$ dominated the composition (Figure $1 \mathrm{~F}$ ). The most abundant MTs in wood were (in the sequence of abundance) $\beta$-pinene $(38 \%)>\alpha$-pinene $(26 \%)>$ limonene \& $\beta$-phellandrene $(7 \%)$ (Figure 3E). Linalool $(6 \%)$ was the most abundant MT-O in wood and - similar to bark - $\alpha$-longipinene $>\beta$-caryophyllene $>$ longifolene - the dominating SQT (Figures 2E and 4E). Only three SQT-Os were identified in wood, which were longiborneol $>$ carotol $>$ oplopanone (Figure 5E). We also observed trace amounts of three DTs and four oxygenated DTs.

In total, 74 terpenoids were abundant in roots. Similar to bark, MT (78\%) and DT-O (15\%) dominated the terpenoid composition (Figure 1F). The MT $\beta$-pinene was most abundant (27\%), followed by $\alpha$-pinene $(24 \%)$, camphene $(12 \%)$ as well as limonene \& $\beta$-phellandrene (8\%) (Figure 3F). Manoyl oxide (7\%) and methyl dehydroabietate $(6 \%)$ were the most important DT-Os in roots.

Terpenoids in current-year needles contained 50\% MT-O, 20\% SQT-O, 18\% MT, 10\% SQT and traces of DT and DT-O (Figure 1F). Camphor (MT-O, 22 $\pm 4 \mathrm{mg} \mathrm{g}^{-1} \mathrm{DW}$ ), $\alpha$-cadinol (SQT-O, $17 \pm 4 \mathrm{mg} \mathrm{g}^{-1} \mathrm{DW}$ ), bornyl acetate (MT-O, $16 \pm 5 \mathrm{mg} \mathrm{g}^{-1} \mathrm{DW}$ ) and camphene (MT, $11 \pm 2 \mathrm{mg} \mathrm{g}^{-1} \mathrm{DW}$ ) were the most abundant 
compounds stored in needles (Figures 2B, 3B, 4B and 5B). The terpenoid contents in previous-year needles showed very similar contents and composition with current-year needles (data not shown).

\section{Common compounds in xylem sap and Norway spruce tissues}

To get hints on possible sources for terpenoids in the xylem sap, all terpenoids identified in xylem sap, bark, wood as well as roots were tested for common abundance (Venn diagram, Figure 7). P-menth-2-en-1-ol and $\alpha$-farnesene exclusively occurred in xylem sap, but not in bark, wood or roots (Figure 7, Table S4). On the other hand, 17 terpenoids were only found in bark, 4 only in wood and 13 terpenoids only in roots (Figure 7, Table S3). The MT-O nopol was only present in xylem sap and roots (Figure 7, Table S3). In an additional approach, emitted terpenoids, and terpenoids identified in xylem sap and needles were also compared (Venn diagram, Figure 8). Spruce needles emitted almost all identified terpenoids present in xylem sap into the atmosphere except p-menth-2-en-1-ol and the two oxygenated SQTs $\delta$-cadinol and oplopanone (Figure 8, Table S5). Importantly, among the emitted compounds, four terpenoids (citronellyl propionate, sclareol, perilla aldehyde, $\alpha$-farnesene) were absent in needles, but occurred in xylem sap (Figure 8, Table S5).

\section{Discussion}

Our main goal was to elucidate if terpenoids are transported in the transpiration stream of Norway spruce, for which we obtained clear evidence. Particularly striking was the high portion of oxygenated terpenoids in xylem sap. This observation is consistent with their Henry's law coefficients. For example, the water solubility of linalool ranges around $10 \mathrm{mmol} \mathrm{L}^{-1}$ (i.e. 1,600 $\mu \mathrm{g} \mathrm{mL} \mathrm{m}^{-1}$ ) (Copolovici \& Niinemets, 2005; Table $\mathrm{S} 2$ ), thus easily allowing the linalool concentrations observed, which were $10^{3}$-times lower (up to $1.6 \mu \mathrm{g} \mathrm{mL}^{-1}$ ). Similarly, the concentrations of other terpenoids were lower than their assumed solubility. For example, 1,8cineole concentrations in xylem sap amounted to $198 \pm 57 \mathrm{ng} \mathrm{mL}-1$, but water solubility is $16.0-22.7$ mol $\mathrm{m}^{-3}$ (equals 2.47-3.50 mg mL $\mathrm{m}^{-1}$ ) and $\beta$-pinene was abundant at concentrations of $238 \pm 160 \mathrm{ng} \mathrm{mL}^{-1}$ with an

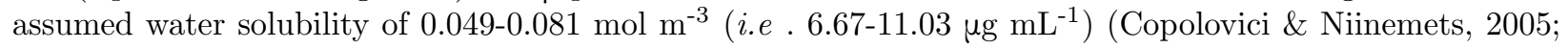
Table S2). In general, also the concentrations of most SQTs were lower than the maximum estimated from water solubility. Nevertheless, there were a few exceptions; the concentration of $\alpha$-farnesene amounted to $35 \pm 4 \mathrm{ng} \mathrm{mL}^{-1}$ in xylem sap although it is not expected to exceed $11 \mathrm{ng} \mathrm{mL} \mathrm{m}^{-1}$ according to its estimated water solubility (Table S2). Similarly, the concentrations of sclareol and manoyl oxide were somewhat higher than their estimated water solubilities (Table S2). Such discrepancies might be due to, effects of temperature, ambient pressure, $\mathrm{pH}$ and presence of other compounds in the solution. Moreover, the water solubility of DT-Os has been estimated from Log $\mathrm{K}_{\mathrm{ow}}$ (WSKOW v1.41) but not from real measurements (ChemSpider, 2018). Most importantly, knowledge of water solubility allows estimation of equilibrium concentrations. If, however, the surrounding tissue of xylem sap contains higher concentrations of individual compounds, higher concentrations in xylem sap will be the consequence.

A second objective of our work was to understand if xylem transported terpenoids might contribute to terpenoid emission from Norway spruce needles. This idea is supported by the observation that many terpenoids present in xylem sap were emitted from needles (Figure 8). Thirteen these compounds were absent or only present in traces in needle tissue (blue highlighted columns in Figs. 2-5) and, hence, their emission might partially be controlled by xylem transport. Of course, we cannot exclude that emission of these compounds was partially or even fully driven byde novo biosynthesis in needles. To differentiate between sources for emission, ${ }^{13}$ C-tracer studies should be performed in future studies. Noteworthy, total terpenoid emission from Norway spruce in our work amounted to $1.8 \mu \mathrm{g} \mathrm{g}^{-1} \mathrm{DW} \mathrm{h}^{-1}$ which is comparable though in the lower range of earlier studies (0.5-12 $\mu \mathrm{g} \mathrm{g}^{-1} \mathrm{DW} \mathrm{h}^{-1}$, Bourtsoukidis et al., 2014; Martin et al., 2003; Yassaa et al., 2012). Larger discrepancies were observed in the composition because the monoterpenoid fraction was smaller in earlier work than in our study (8\%, based on results from Martin et al. (2003); 40\%, from our present work). Such discrepancies might be caused by differences in genotype and/or site conditions. Since especially 1,8-cineole and linalool were highly abundant stress might also play a role as these compounds 
are induced by stress (Blande, Turunen \& Holopainen, 2009; Kannaste et al., 2009; Martin et al., 2003). However, we did not observe any sign of stress in our experimental trees.

Besides being emitted, xylem transported compounds can also be taken up by mesophyll cells and be channeled into cellular metabolism, as demonstrated for short-chained oxygenated VOC (acetaldehyde, ethanol) (Kreuzwieser, Scherer \& Rennenberg, 1999; Kreuzwieser et al. 2000, 2001; Rissanen, Hölttä \& Bäck, 2018). These compounds either accumulate in leaf cells or being metabolized or converted to other monoterpenoid species (Niinemets et al., 2014). Our work provided hints that p-menth-2-en-1-ol and $\delta$-cadinol were converted to other compounds, since they were neither emitted nor detectable in needle tissue although clearly abundant in the xylem sap. In contrast, the sesquiterpenoid oplopanone seemed to accumulate in needles, which fits to reports indicating oplopanone in needles of several conifer species (Larix kaempferi : Tanaka, Ohtsu \& Matsunaga, 1997; Chamaecyparis formosensis : Lin, Fang \& Cheng, 1999; Cryptomeria japonica : $\mathrm{Su}$, Fang \& Cheng, 1995).

The finding of terpenoids in the xylem sap poses the question on possible sources for these compounds. Our data allow speculation on the origin of at least some of the compounds. For example, xylem sap abundant nopol was detected only in roots, but not in wood or bark, suggesting that this compound was produced in roots and loaded into the xylem. Nopol was not found in Norway spruce before, but its abundance has been demonstrated in needles of other conifers (Picea orientalis : Ucar, Balaban \& Usta, 2003; Pinus spp: Mateus, 2009), and oil of rosemary (Tounekti et al., 2011) and Eucalyptus olida (Gilles et al., 2010).

Since terpenoids are biosynthesized mainly in close vicinity to the cambium and stored nearby in secretory tissue such as resin canals or resin ducts and their surrounding epithelial cells (Back, 2002), diffusive transfer from these compartments into the xylem vessels might occur. Still, it has to be taken into account that epithelial cells and resin ducts are strongly lignified which might reflect a barrier for diffusion of terpenoids to the outside of such structures. The abundance of $\delta$-cadinol in bark and xylem sap, but its absence in roots and wood, suggests that this sesquiterpenoid was formed in bark and loaded into the xylem. However, for most of the other terpenoids present in xylem sap it is not possible to conclude on possible sources since they were abundant in root, wood and bark tissue, and therefore can be derived from all of them.

Importantly, the terpenoid composition in xylem sap differed considerably from that of spruce needles, bark, wood and roots (Figure 6). Some compounds such as the MT-Os bornyl acetate and isoborneol which were highly abundant in bark and wood were not even present in traces in xylem sap. For this reason, we can exclude that terpenoids in xylem sap are a result of contamination from residues of resin during cutting the twigs for xylem sap collection. From a physiological point of view, the results suggest that terpenoids are not just leaking from any of the studied tissue/resin ducts into the xylem sap. This assumption rises the questions, whether (i) xylem transport of terpenoids has to be considered active transport processes allowing at least partial control of compounds released into this apoplastic space, and, consequently, (ii) whether any function is related to long-distance transport of terpenoids. Transport of terpenoids across the plasmalemma into the apoplast might be mediated by secretion; this process has been demonstrated for transport of terpenoids into glandular trichomes (Dai et al., 2010; Lange \& Turner, 2013; Martin et al., 2009; Tissier, 2012; Tissier, Morgan \& Dudareva, 2017). On the other hand, active terpenoid transport requiring the consumption of ATP has been also proposed, which might be mediated by ATP binding cassette $(\mathrm{ABC})$-transporters. This was indirectly concluded from the common sites of terpenoid biosynthesis and expression of such transporters in glandular trichomes (Adebesin et al., 2017; Aziz et al., 2005; Bertea et al., 2006; Chatzopoulou et al., 2010; Harada et al., 2010; Lange et al., 2000; Schilmiller et al., 2010; Wang et al., 2008, 2016; Yazaki, 2006). Moreover, such transporters seem to be responsible for export of diterpenes (e.g. sclareol, manool, cembrene) and sesquiterpenes (e.g. $\beta$-caryophyllene, capsidiol) (Campbell et al., 2003; Crouzet et al. 2013; Fu et al., 2017; Jasiński et al. 2001; Pierman et al., 2017; Seo et al. 2012; Van den Brûle et al., 2002) and are also thought to be involved in monoterpene export (Tissier et al., 2017). Both, secretion via vesicles and membrane transport through ABC-transporters might in addition be connected to cell internal transfer by lipophilic transfer proteins (LPTs), which channel the compounds from the sites of production (e.g. chloroplasts) towards the plasma membrane (Tissier et al., 2017). Still, this is 
still speculative and experiments have to be conducted to obtain deeper insight.

To summarize, we demonstrated that a considerable amount of terpenoids is transported in the xylem sap of Norway spruce. In accordance with the Henry's constants, the transpiration stream mainly contained oxygenated terpenoids and hydrocarbon terpenes to a less extent. The very different terpenoid patterns in the different plant tissues investigated compared to the xylem sap, indicates that xylem loading of terpenoids is a controlled process posing the question of possible functions of transported terpenoids. Future studies should therefore particularly focus on the origin and functions of xylem sap transported terpenoids in conifers.

\section{Acknowledgement}

Qiuxiao Duan greatly acknowledges support from the China Scholarship Council (CSC, Grant \#2011630183), Landesgraduiertenförderungsgesetz (LGFG) Baden-Württemberg, German Academic Exchange Service (DAAD) as well as University of Freiburg, Germany.

\section{Conflict of interest}

The authors declare that they have no conflicts of interest.

\section{Reference}

Adebesin, F., Widhalm, J.R., Boachon, B., Lefèvre, F., Pierman, B., Lynch, J.H., Alam, I., Junqueira, B., Benke, R., Ray, S. \& Porter, J.A. (2017) Emission of volatile organic compounds from petunia flowers is facilitated by an ABC transporter. Science 356 , 1386-1388.

Axelsson, K., Zendegi-Shiraz, A., Swedjemark, G., Borg-Karlson, A.K. \& Zhao, T. (2016) Clone specific chemical defense responses in Norway spruce to infestations by two pathogenic fungi. Forest Pathology .

Aziz, N., Paiva, N.L., May, G.D. \& Dixon, R.A. (2005) Transcriptome analysis of alfalfa glandular trichomes. Planta 221, 28-38.

Back, E.L. (2002) Pattern of parenchyma and canal resin composition in softwoods and hardwoods. Journal of wood science $48,167-170$.

Bäck, J., Aalto, J., Henriksson, M., Hakola, H., He, Q. \& Boy, M. (2012) Chemodiversity of a Scots pine stand and implications for terpene air concentrations. Biogeosciences 9 , 689-702.

Bertea, C.M., Voster, A., Verstappen, F.W., Maffei, M., Beekwilder, J. \& Bouwmeester, H. J. (2006) Isoprenoid biosynthesis in Artemisia annua : cloning and heterologous expression of a germacrene A synthase from a glandular trichome cDNA library. Archives of Biochemistry and Biophysics 448 , 3-12.

Blanch, J.S., Penuelas, J., Sardans, J. \& Llusia, J. (2009) Drought, warming and soil fertilization effects on leaf volatile terpene concentrations in Pinus halepensis and Quercus ilex.Acta Physiologiae Plantarum 31 , 207.

Blande, J. D., Turunen, K. \& Holopainen, J. K. (2009) Pine weevil feeding on Norway spruce bark has a stronger impact on needle VOC emissions than enhanced ultraviolet-B radiation. Environmental Pollution $157,174-180$.

Bourtsoukidis, E., Bonn, B., Dittmann, A., Hakola, H., Hellén, H. \& Jacobi, S. (2012) Ozone stress as a driving force of sesquiterpene emissions: a suggested parameterisation. Biogeosciences $\mathbf{9}$, 4337-4352. 
Bourtsoukidis, E., Williams, J., Kesselmeier, J., Jacobi, S. \& Bonn, B. (2014) From emissions to ambient mixing ratios: online seasonal field measurements of volatile tissueic compounds over a Norway sprucedominated forest in central Germany. Atmospheric Chemistry and Physics 14, 6495-6510.

Bufler, U., Seufert, G. \& Jüttner, F. (1990) Monoterpene patterns of different tissues and plant parts of Norway spruce (Picea abiesL. Karst.). Environmental Pollution 68 , 367-375.

Campbell E.J., Schenk P.M., Kazan K., Penninckx I.A., Anderson J.P., Maclean D.J., Cammue B.P., Ebert P.R. \& Manners J.M. (2003) Pathogen-responsive expression of a putative ATP-binding cassette transporter gene conferring resistance to the diterpenoid sclareol is regulated by multiple defense signaling pathways in Arabidopsis.Plant Physiolog y 133, 1272-1284.

Chatzopoulou, F.M., Makris, A.M., Argiriou, A., Degenhardt, J. \& Kanellis, A.K. (2010) EST analysis and annotation of transcripts derived from a trichome-specific cDNA library from Salvia fruticosa .Plant Cell Reports 29 , 523-534.

ChemSpider, 2018: http://www.chemspider.com/

Chong, J., Soufan, O., Li, C., Caraus, I., Li, S., Bourque, G., Wishart, D.S. \& Xia, J. (2018) MetaboAnalyst 4.0: towards more transparent and integrative metabolomics analysis. Nucleic acids research . https://doi.org/10.1093/nar/gky310

Copolovici, L.O. \& Niinemets, Ü. (2005) Temperature dependencies of Henry's law constants and octanol/water partition coefficients for key plant volatile monoterpenoids. Chemosphere 61, 1390-1400.

Crouzet, J., Roland, J., Peeters, E., Trombik, T., Ducos, E., Nader, J. \& Boutry, M. (2013) NtPDR1, a plasma membrane $\mathrm{ABC}$ transporter fromNicotiana tabacum, is involved in diterpene transport.Plant Molecular Biology 82, 181-192.

Dai, X., Wang, G., Yang, D.S., Tang, Y., Broun, P., Marks, M.D. Sumner, L.W., Dixon, R.A \& Zhao, P.X. (2010) TrichOME: a comparative omics database for plant trichomes. Plant Physiology 152 , 44-54.

Dudareva, N., Klempien, A., Muhlemann, J. K., \& Kaplan, I. (2013) Biosynthesis, function and metabolic engineering of plant volatile tissueic compounds. New Phytologist , $198,16-32$.

DWD, 2015: Deutscher Wetterdienst. https://www.dwd.de

Fichan, I., Larroche, C. \& Gros, J. B. (1999) Water solubility, vapor pressure, and activity coefficients of terpenes and terpenoids.Journal of Chemical and Engineering Data 44, 56-62.

Filella, I., Wilkinson, M.J., Llusia, J., Hewitt, C.N. \& Peñuelas, J. (2007). Volatile organic compounds emissions in Norway spruce (Picea abies) in response to temperature changes.Physiologia Plantarum 130 , $58-66$.

Flo, D., Norli, H. R., Økland, B. \& Krokene, P. (2018) Successful reproduction and pheromone production by the spruce bark beetle in evolutionary naïve spruce hosts with familiar terpenoid defences.Agricultural and Forest Entomology . https:// doi.org/10.1111/afe.12280

Fu, X., Shi, P., He, Q., Shen, Q., Tang, Y., Pan, Q., Ma, Y., Yan, T., Chen, M., Hao, X. \& Liu, P. (2017) AaPDR3, a PDR transporter 3, is involved in sesquiterpene $\beta$-caryophyllene transport in Artemisia annua . Frontiers in Plant Science 8, 723.

Gershenzon J \& Croteau R (1991) Terpenoids. In: Herbivores, their interactions with secondary Metabolites (eds G.A. Rosenthal \& M.R. Berbembaum), pp. 165-219. Academic Press, New York, NY.

Gershenzon, J., \& Dudareva, N. (2007) The function of terpene natural products in the natural world. Nature Chemical Biology ,3, 408. 
Ghirardo, A., Koch, K., Taipale, R., Zimmer, I.N.A., Schnitzler, J. P. \& Rinne, J. (2010) Determination of de novo and pool emissions of terpenes from four common boreal/alpine trees by ${ }^{13} \mathrm{CO} 2$ labelling and PTR-MS analysis. Plant, Cell and Environment 33 , 781-792.

Gilles, M., Zhao, J., An, M. \& Agboola, S. (2010) Chemical composition and antimicrobial properties of essential oils of three AustralianEucalyptus species. Food Chemistry 119 , 731-737.

Grabmer, W., Kreuzwieser, J., Wisthaler, A., Cojocariu, C., Graus, M., Rennenberg, H., Steigner, D., Steinbrecher, R. \& Hansel, A. (2006) VOC emissions from Norway spruce (Picea abies L.[Karst]) twigs in the field-results of a dynamic enclosure study. Atmospheric Environment 40, 128-137.

Guenther, A.B., Zimmerman, P.R., Harley, P.C., Monson, R.K. \& Fall, R. (1993) Isoprene and monoterpene emission rate variability: model evaluations and sensitivity analyses. Journal of Geophysical Research: Atmospheres 98 , 12609-12617.

Harada, E., Kim, J.A., Meyer, A.J., Hell, R., Clemens, S. \& Choi, Y.E. (2010) Expression profiling of tobacco leaf trichomes identifies genes for biotic and abiotic stresses. Plant and Cell Physiology51, 1627-1637.

Jasiński M., Stukkens Y., Degand H., Purnelle B., Marchand-Brynaert J. \& Boutry M. (2001) A plant plasma membrane ATP binding cassette-type transporter is involved in antifungal terpenoid secretion. The Plant Cell 13 , 1095-1107.

Kannaste, A., Nordenhem, H., Nordlander, G. \& Borg-Karlson, A.-K. (2009). Volatiles from a mite-infested spruce clone and their effects on pine weevil behaviour. Journal of Chemical Ecology 35 , 1262-1271.

Kleiber, A., Duan, Q., Jansen, K., Verena Junker, L., Kammerer, B., Rennenberg, H., Ensminger, I., Gessler, A. \& Kreuzwieser, J. (2017) Drought effects on root and needle terpenoid content of a coastal and an interior Douglas fir provenance. Tree physiology 37 , 1648-1658.

Kreuzwieser, J., Harren, F.J., Laarhoven, L.J., Boamfa, I., Te Lintel-Hekkert, S., Scheerer, U., Hüglin, C. \& Rennenberg, H. (2001) Acetaldehyde emission by the leaves of trees-correlation with physiological and environmental parameters. Physiologia Plantarum113, 41-49.

Kreuzwieser, J., Kühnemann, F., Martis, A., Rennenberg, H. \& Urban, W. (2000) Diurnal pattern of acetaldehyde emission by flooded poplar trees.Physiologia Plantarum 108, 79-86.

Kreuzwieser, J., Scheerer, U. \& Rennenberg, H. (1999) Metabolic origin of acetaldehyde emitted by poplar $($ Populus tremula $\times$ P. alba $)$ trees. Journal of Experimental Botany 50 , 757-765.

Kuroda, K. (1991). Mechanism of cavitation development in the pine wilt disease. European Journal of Forest Pathology 21, 82-89.

Lange, B. M. \& Turner, G. W. (2013) Terpenoid biosynthesis in trichomes - current status and future opportunities. Plant Biotechnology Journal 11, 2-22.

Lange, B. M., Wildung, M. R., Stauber, E. J., Sanchez, C., Pouchnik, D. \& Croteau, R. (2000) Probing essential oil biosynthesis and secretion by functional evaluation of expressed sequence tags from mint glandular trichomes. Proceedings of the National Academy of Sciences97, 2934-2939.

Lin, T.C., Fang, J.M. \& Cheng, Y.S. (1999) Terpenes and lignans from leaves of Chamaecyparis formosensis . Phytochemistry51, 793-801.

Loreto F., Ciccioli P., Cecinato A., Brancaleoni E., Frattoni M., Fabozzi C. \& Tricoli D. (1996) Evidence of the photosynthetic origin of monoterpenes emitted by Quercus ilex L. leaves by ${ }^{13} \mathrm{C}$ labeling. Plant Physiology $110,1317-1322$.

Loreto, F., Mannozzi, M., Maris, C., Nascetti, P., Ferranti, F., \& Pasqualini, S. (2001) Ozone quenching properties of isoprene and its antioxidant role in leaves. Plant Physiology 126, 993-1000. 
Loreto F., Nascetti P., Graverini A. \& Mannozzi M. (2000) Emission and content of monoterpenes in intact and wounded needles of the Mediterranean pine, Pinus pinea. Functional Ecology14, 589-595.

Loreto, F., Pollastri, S., Fineschi, S. \& Velikova, V. (2014). Volatile isoprenoids and their importance for protection against environmental constraints in the Mediterranean area. Environmental and experimental botany $103,99-106$.

Loreto, F. \& Schnitzler, J. P. (2010). Abiotic stresses and induced BVOCs. Trends in plant science 15 , 154-166.

Martin, D.M., Gershenzon, J. \& Bohlmann, J. (2003) Induction of volatile terpene biosynthesis and diurnal emission by methyl jasmonate in foliage of Norway spruce. Plant Physiology 132, 1586-1599.

Martin, D., Tholl, D., Gershenzon, J. \& Bohlmann, J. (2002) Methyl jasmonate induces traumatic resin ducts, terpenoid resin biosynthesis, and terpenoid accumulation in developing xylem of Norway spruce stems.Plant Physiology 129, 1003-1018.

Martin, D.M., Toub, O., Chiang, A., Lo, B.C., Ohse, S., Lund, S.T. \& Bohlmann, J. (2009) The bouquet of grapevine (Vitis vinifera L. cv. Cabernet Sauvignon) flowers arises from the biosynthesis of sesquiterpene volatiles in pollen grains. Proceedings of the National Academy of Sciences , pnas-0901387106.

Mateus, E. P. (2009) Characterization of Pinus spp. needles by gas chromatography and mass spectrometry: Application to plant-insect interactions. Ph.D. thesis, Faculty of Sciences and

Technology, Universidade Nova de Lisboa.

McGarvey, D. J. \& Croteau, R. (1995) Terpenoid metabolism. The Plant Cell , 7 , 1015.

Merk, L., Kloos, M., Schönwitz, R. \& Ziegler, H. (1988) Influence of various factors on quantitative composition of leaf monoterpenes of Picea abies (L.) Karst. Trees 2 , 45-51.

Muhlemann, J. K., Klempien, A. \& Dudareva, N. (2014). Floral volatiles: from biosynthesis to function. Plant, cell E environment37, 1936-1949.

Nagegowda, D. A. (2010). Plant volatile terpenoid metabolism: biosynthetic genes, transcriptional regulation and subcellular compartmentation. FEBS letters 584, 2965-2973.

Nagel, R., Berasategui, A., Paetz, C., Gershenzon, J. \& Schmidt, A. (2014) Overexpression of an isoprenyl diphosphate synthase in spruce leads to unexpected terpene diversion products that function in plant defense. Plant Physiology 164, 555-569.

Niinemets, Ü., Fares, S., Harley, P. \& Jardine, K.J. (2014) Bidirectional exchange of biogenic volatiles with vegetation: emission sources, reactions, breakdown and deposition. Plant, Cell and Environment 37 , 17901809.

Persson, M., Borg-Karlson, A.K. \& Norin, T. (1993) Enantiomeric composition of six chiral monoterpene hydrocarbons in different tissues of Picea abies . Phytochemistry 33, 303-307.

Pierman, B., Toussaint, F., Bertin, A., Levy, D., Smargiasso, N., De Pauw, E. \& Boutry, M. (2017) Activity of the purified plant ABC transporter NtPDR1 is stimulated by diterpenes and sesquiterpenes involved in constitutive and induced defenses. Journal of Biological Chemistry 292 , 19491-19502.

Prieme, A., Knudsen, T. B., Glasius, M. \& Christensen, S. (2000) Herbivory by the weevil, Strophosoma melanogrammum, causes severalfold increase in emission of monoterpenes from young Norway spruce (Picea abies ). Atmospheric Environment 34, 711-718.

Rennenberg, H., Schneider, S. \& Weber, P. (1996) Analysis of uptake and allocation of nitrogen and sulphur compounds by trees in the field.Journal of Experimental Botany $47,1491-1498$. 
Rissanen, K., Hölttä, T. \& Bäck, J. (2018) Transpiration directly regulates the emissions of water-soluble short-chained OVOCs.Plant, Cell and Environment 41, 2288-2298.

Schilmiller, A.L., Miner, D.P., Larson, M., McDowell, E., Gang, D.R., Wilkerson, C. \& Last, R.L. (2010) Studies of a biochemical factory: tomato trichome deep expressed sequence tag sequencing and proteomics. Plant Physiology 153, 1212-1223.

Schmidt, A., Nagel, R., Krekling, T., Christiansen, E., Gershenzon, J. \& Krokene, P. (2011) Induction of isoprenyl diphosphate synthases, plant hormones and defense signalling genes correlates with traumatic resin duct formation in Norway spruce (Picea abies ). Plant molecular biology 77 , 577-590.

Schönwitz, R., Lohwasser, K., Kloos, M. \& Ziegler, H. (1990) Seasonal variation in the monoterpenes in needles of Picea abies (L.) Karst. Trees 4 , 34-40.

Schürmann, W., Ziegler, H., Kotzias, D., Schönwitz, R. \& Steinbrecher, R. (1993) Emission of biosynthesized monoterpenes from needles of Norway spruce. Naturwissenschaften 80, 276-278.

Seo, S., Gomi, K., Kaku, H., Abe, H., Seto, H., Nakatsu, S., Neya, M., Kobayashi, M., Nakaho, K., Ichinose, Y. \& Mitsuhara, I. (2012) Identification of natural diterpenes that inhibit bacterial wilt disease in tobacco, tomato and Arabidopsis. Plant and Cell Physiology53, 1432-1444.

Su, W.C., Fang, J.M. \& Cheng, Y.S. (1995) Sesquiterpenes from leaves ofCryptomeria japonica . Phytochemistry 39, 603-607.

Tanaka, R., Ohtsu, H. \& Matsunaga, S. (1997) Abietane diterpene acids and other constituents from the leaves of Larix kaempferi .Phytochemistry 46 , 1051-1057.

Tingey D.T., Manning M., Grothaus L.C. \& Burns W.F. (1979) The influence of light and temperature on isoprene emission rates from live oak. Plant Physiology $47,112-118$.

Tissier, A. (2012) Glandular trichomes: what comes after expressed sequence tags? The Plant Journal 70 , 51-68.

Tissier, A., Mtissue, J.A. \& Dudareva, N. (2017) Plant volatiles: going 'in' but not 'out' of trichome cavities. Trends in Plant Sciences 22, 930-938.

Tounekti, T., Vadel, A.M., Ennajeh, M., Khemira, H. \& Munné-Bosch, S. (2011) Ionic interactions and salinity affect monoterpene and phenolic diterpene composition in rosemary (Rosmarinus officinalis ). Journal of Plant Nutrition and Soil Science 174, 504-514.

Trapp, S. C. \& Croteau, R. B. (2001). Genomic organization of plant terpene synthases and molecular evolutionary implications. Genetics 158, 811-832.

Turtola, S., Manninen, A. M., Rikala, R. \& Kainulainen, P. (2003) Drought stress alters the concentration of wood terpenoids in Scots pine and Norway spruce seedlings. Journal of Chemical Ecology29, 1981-1995.

Ucar, G., Balaban, M. \& Usta, M. (2003) Volatile needle and wood extracts of oriental spruce Picea orientalis (L.) Link. Flavour and Fragrance Journal 18, 368-375.

Van den Brûle S., Muller A., Fleming A.J. \& Smart C.C. (2002) The ABC transporter SpTUR2 confers resistance to the antifungal diterpene sclareol. The Plant Journal 30 , 649-662.

Vickers, C.E., Possell, M., Cojocariu, C.I., Velikova, V.B., Laothawornkitkul, J., Ryan, A., Mullineaux, P.M. \& Nicholas Hewitt, C. (2009). Isoprene synthesis protects transgenic tobacco plants from oxidative stress. Plant, Cell E⿱ Environment 32, 520-531.

Wang B., Kashkooli A.B., Sallets A., Ting H.M., de Ruijter N.C.A., Olofsson L., Brodelius P., Brodelius, P., Pottier, M., Boutry, M., Bouwmeester, H. \& van der Krol A.R. (2016) Transient production of artemisinin in Nicotiana benthamiana is boosted by a specific lipid transfer protein from A. annua. Metabolic Engineering $38,159-169$. 
Wang, G., Tian, L., Aziz, N., Broun, P., Dai, X., He, J., King, A., Zhao, P.X. \& Dixon, R. A. (2008) Terpene biosynthesis in glandular trichomes of hop. Plant physiology $148,1254-1266$.

Wu, H. \& Hu, Z. H. (1997). Comparative anatomy of resin ducts of the Pinaceae. Trees 11, 135-143.

Wu, C., Pullinen, I., Andres, S., Kiendler-Scharr, A., Kleist, E., Wahner, A., Wildt, J. \& Mentel, T.F. (2017)

${ }^{13} \mathrm{C}$ labelling study of constitutive and stress-induced terpenoide missions from Norway spruce and Scots pine. Biogeosciences Discussions .https://doi.org/10.5194/bg-2017-260

Yassaa, N., Song, W., Lelieveld, J., Vanhatalo, A., Bäck, J. \& Williams, J. (2012). Diel cycles of isoprenoids in the emissions of Norway spruce, four Scots pine chemotypes, and in Boreal forest ambient air during HUMPPA-COPEC-2010. Atmosheric Chemistry and Physics12, 7215-7229.

Yazaki, K. (2006) ABC transporters involved in the transport of plant secondary metabolites. FEBS letters $\mathbf{5 8 0}, 1183-1191$.

Zeneli, G., Krokene, P., Christiansen, E., Krekling, T. \& Gershenzon, J. (2006) Methyl jasmonate treatment of mature Norway spruce (Picea abies ) trees increases the accumulation of terpenoid resin components and protects against infection by Ceratocystis polonica, a bark beetle-associated fungus. Tree Physiology $\mathbf{2 6}$, 977-988.

Zhao, T., Krokene, P., Björklund, N., Langström, B., Solheim, H., Christiansen, E. \& Borg-Karlson, A.K. (2010) The influence ofCeratocystis polonica inoculation and methyl jasmonate application on terpene chemistry of Norway spruce, Picea abies .Phytochemistry , 71, 1332-1341.

Zhao, T., Krokene, P., Hu, J., Christiansen, E., Björklund, N., Langström, B., Solheim, H. \& Borg-Karlson, A.K. (2011a) Induced terpene accumulation in Norway spruce inhibits bark beetle colonization in a dosedependent manner. PLoS One 6 , e26649.

Zhao, T., Solheim, H., Langström, B., \& Borg-Karlson, A.K. (2011b) Storm-induced tree resistance and chemical differences in Norway spruce (Picea abies ). Annals of forest science 68, 657-665.

\section{Figure legends}

Figure 1. Total terpenoid contents in xylem sap (A), total terpenoid emissions (B) and total terpenoid contents in different tissues (C) as well as terpenoid composition in xylem sap (D), of emissions (E), and in different tissues (F) of Norway spruce trees. Data are means $\pm \mathrm{SE}$ of at least five biological replicates each. MT, monoterpenes; MT-O, oxygenated monoterpenoids; SQT, sesquiterpenes; SQT-O, oxygenated sesquiterpenoids; DT, diterpenes; DT-O, oxygenated diterpenoids. Different letters indicate significant difference at $\mathrm{p}<0.05$ by ANOVA on ranks.

Figure 2. Emission rates (A), and contents/concentrations of the 16 most abundant oxygenated monoterpenoids in current-year needles (B), xylem sap (C), bark (D), wood (E), and roots (F) of Norway spruce trees. Data are means $\pm \mathrm{SE}$ of at least five biological replicates. All compounds emitted but under-represented in needles are highlighted in blue.

Figure 3. Emission rates (A), and contents/concentrations of the 10 most abundant monoterpenes in currentyear needles (B), xylem sap (C), bark (D), wood (E), and roots (F) of Norway spruce trees. Data are means $\pm \mathrm{SE}$ of at least five biological replicates. All compounds emitted but not present in needles are highlighted in blue.

Figure 4. Emission rates (A), and contents/concentrations of the 11 most abundant sesquiterpenes in currentyear needles (B), xylem sap (C), bark (D), wood (E), and roots (F) of Norway spruce trees. Data are means $\pm \mathrm{SE}$ of at least five biological replicates. All compounds emitted but absent or under-represented in needles are highlighted in blue. 
Figure 5. Emission rates (A), and contents/concentrations of the 8 most abundant oxygenated sesquiterpenoids in current-year needles (B), xylem sap (C), bark (D), wood (E), and roots (F) of Norway spruce trees. Data are means $\pm \mathrm{SE}$ of at least five biological replicates. All compounds emitted but under-represented in needles are highlighted in blue.

Figure 6. Score plot of a partial least-square discriminant analysis (PLS-DA) of the terpenoid contents in xylem sap, bark, wood, current-year needles and roots of Norway spruce under natural condition in 2015. The loading plot, which indicates the terpenoids that are responsible for the sample distribution in the score plot, is given in Figure S1 available as Supplementary Data at Plant Cell and Environment online.

Figure 7. Venn plot indicating the numbers of terpenoids present in roots, bark, wood and xylem sap of Norway spruce (graph drawn online:http://bioinformatics.psb.ugent.be/webtools/Venn/and the specific compounds were shown in Table S3).

Figure 8. Venn plot indicating the numbers of terpenoids present in needles, emissions and xylem sap of spruce (graph drawn online:http://bioinformatics.psb.ugent.be/webtools/Venn/and the specific compounds were shown in Table S4).

\section{Hosted file}

Figures-revision.docx available at https://authorea.com/users/300429/articles/430072terpenoids-are-transported-in-the-xylem-sap-of-norway-spruce 